\title{
Balkanologie
}

Balkanologie Revue d'études pluridisciplinaires

Vol. VI, $n^{\circ}$ 1-2 | 2002

Volume VI Numéro 1-2

\section{Hadžieva-Aleksievska (Jasmina), Kasapova (Elizabeta), Arhitekt Andreja Damjanov 1813-1878 [Andreja Damjanov, architecte, 1813-1878]}

Skopje, 2001, 230 p.

Bernard Lory

\section{(2) OpenEdition}

Journals

Édition électronique

URL : http://journals.openedition.org/balkanologie/1932

DOI : 10.4000/balkanologie.1932

ISSN : 1965-0582

Éditeur

Association française d'études sur les Balkans (Afebalk)

Édition imprimée

Date de publication : 1 décembre 2002

Pagination : 285-286

ISSN : 1279-7952

Référence électronique

Bernard Lory, « Hadžieva-Aleksievska (Jasmina), Kasapova (Elizabeta), Arhitekt Andreja Damjanov 1813-1878 [Andreja Damjanov, architecte, 1813-1878] », Balkanologie [En ligne], Vol. VI, n 1-2 | 2002, mis en ligne le 04 février 2009, consulté le 17 décembre 2020. URL : http://journals.openedition.org/ balkanologie/1932 ; DOI : https://doi.org/10.4000/balkanologie.1932 
fonds appartenant à la liste de ses sources. Il décide également de ne pas utiliser certrains fonds des Archives diplomatiques (Albanie, vol. 14/15) et inverse après délibérément la suite chronologique des événements de l'été et de l'automne 1920. Voici le résultat de cette observation : "A l'été, l'armée SHS marche sur Scuttari et Tirana. Le gouvernement albanais mobilise et remporte, le 26 août, la victoire, accusant les Yougoslaves de "vouloir exterminer" la race albanaise " (p. 105). Cette description est complètement à l'opposé de la réalité des faits et des intentions serbes. Premièrement, ne mentionnant pas délibérément le fait que Franchet d'Esperey, le commandant en chef à l'époque, avait dès 1918 déterminé des lignes de démarcation, l'auteur insiste sur " l'occupation " serbe et sur son plan pour diviser l'Albanie en " parts égales ". Tout est arrangé par les mémorandums albanais bien connus, présentés aux forums internationaux et aux Grandes Puissances séparément, et aussi par la propagande venant d'Italie et de Grande-Bretagne. Hormis les livres et les articles qu'il omet, délibérément ou non, d'utiliser, Grumel-Jacquignon n'hésite pas, dans le même temps, à ériger certains travaux en "ouvrages capitaux", comme par exemple le livre de Paul Garde (Vie et mort de la Yougoslavie, 1992) pour lequel l'auteur affirme que c'est " l'œuvre d'un linguiste qui a le mérite, peu courant en France, de souligner la vision ethnique des Serbes et de relativiser la signification des liens franco-serbes n (p. 623) 15 .

François Grumel-Jacquignon nous a convaincu sur plusieurs points, mais malheureusement pas sur ceux qu'il espérait. Sa présentation à la lumière des sources extensives et de l'observation des nombreuses controverses intérieures dans les relations entre les Etats balkaniques est une contribution à prendre en compte, mais elle demeure bien loin d'une interprétation des problèmes extérieurs et intérieurs du Royaume de la Yougoslavie et de son attitude vis-à-vis de la France et inversement. L'éditeur Peter Lang, qui a publié des ouvrages importants, comme par exemple deux études exhaustives d'Yvon Lacaze, a contribué avec le livre de Grumel-Jacquignon à un dialogue scientifique, mais non à un grand succès dans le sens professionnel.

Mile Bjelajac

\author{
Hadžieva-Aleksievska [Jasmina], Kasapova (Elizabeta), \\ Arhitekt Andreja Damjanov 1813-1878 \\ [Andreja Damjanov, architecte, 1813-1878], \\ Skopje, 2001, 230 p.
}

Cet ouvrage, publié sous les auspices du Ministère de la Culture de Macédoine et du programme PHARE, présente à la fois en anglais et en macédonien l'œuvre de l'architecte Andreja Damjanov. Celui-ci s'inscrit dans une généalogie d'architectes, peintres d'icônes et sculpteurs d'iconostases célèbres dans les Balkans, le vaste clan des Renzovski-ZografskiDospevski. L'ancêtre commun, au début du XVIII ${ }^{\mathrm{e}}$ siècle, était originaire de la région de Gorna Reka, près de Debar, région de montagne pauvre, dont les habitants s'étaient spécialisés dans

${ }_{15}$ D'autres ouvrages jugés " capitaux " par l'auteur sont mis en avant, en voici une liste non exhaustive : Pribičević (Svetozar), La dictature du Roi Alexandre, 1933 ; Pezet (Ernest), Simondet (Henri), La Yougoslavie en péril, 1933 ; Pozi (Henri), La guerre revient, 1933 ; Adler (Jasna), L'Union forcée. La Croatie et la création de l'Etat yougoslave en 1918, Genève, 1997. Ces ouvrages ont en commun d'être peu impartiaux sur la question serbe. 
les métiers du bâtiment et oeuvrèrent dans tous les Balkans ottomans. Héritier de cette tradition, Andreja Damjanov apprit son métier sur les chantiers. Son œuvre connue, une quarantaine d'églises et de bâtiments civils réalisés entre 1835 et 1878 , se répartit sur les vallées du Vardar et de la Morava, avec une extension intéressante vers la Bosnie-Herzégovine.

L'ouvrage présente de petites monographies sur treize églises : sept sur le territoire de la Macédoine (Skopje, Kratovo, Veles, Sv. Jakim Osogovski, Novo Selo, Kumanovo, Gorno Čičevo), quatre en Serbie (Pečenjevac, Turekovac, Niš, Smederevo) et deux en BosnieHerzégovine (Sarajevo, Mostar). Cette dernière a été détruite lors de la récente guerre. Abondamment illustré de photos, plans et coupes, cet ouvrage vient à point nommé pour nous rappeler qu'il est absurde de plaquer des schémas nationaux sur l'histoire de l'art. On voit l'architecte macédonien s'adapter à la demande sociale de ses commanditaires serbes, en combinant simultanément des éléments traditionnels hérités de l'école de la Morava du $\mathrm{XV}^{\mathrm{e}}$ siècle et des éléments baroques occidentaux venus d'outre-Save. Les débats internes de l'orthodoxie balkanique s'organisent visiblement à cette époque beaucoup plus sur un axe tradition-innovation que sur celui de la compétition nationale. 